\title{
P-105
}

\section{Chemical Compounds from A Marine Sponge: Xestospongia sp. and its Biological Activities}

\author{
Habsah Mohamad ${ }^{1,2, *}$, Wan Ainur Najmiah Wan Abdul Jamil ${ }^{2}$, Faridah Abas ${ }^{3,4}$, Khamsah Suryati \\ Mohamad $^{5}$, and Abd Manaf Ali ${ }^{5}$ \\ ${ }^{1}$ Institute of Marine Biotechnology, ${ }^{2}$ Department of Chemical Sciences, Faculty of Science and Technology, Universiti \\ Malaysia Terengganu, $21030 \mathrm{~K}$. Terengganu, Terengganu, Malaysia; ${ }^{3}$ Institute of Biosciences, ${ }^{4}$ Faculty of Food Science \\ and Technology, Universiti Putra Malaysia, 43400 UPM Serdang, Selangor, Malaysia; ${ }^{5}$ Faculty of Agriculture and \\ Biotechnology, Kampus Gong Badak, 21300 Kuala Terengganu, Malaysia; E-mail: habsah@umt.edu.my
}

Four compounds were isolated from the ethyl acetate crude extract of Xestospongia sp., namely benzoic acid, 2-phenylacetic acid, 2-hydroxyl-1 $H$-inden-1-one and 6-styryl-5,6-dihydropyran-2-one. The structures of these compounds were elucidated based on spectroscopic methods including nuclear magnetic resonance (NMR-1D and 2D), UV, IR, mass spectrometry and comparison with literature data. The ethyl acetate extract showed weak antityrosinase and acethylcholinasterase activities. Benzoic acid and 2-phenylacetic acid, were found to posses weak free radical-scavenging activity.

Keywords: Xestospongia, benzoic acid, 2-phenylacetic acid, 2-hydroxyl-1 $H$-inden-1-one and 6-styryl-5,6-dihydropyran-2-one. 